\title{
COMPARISON OF APGAR SCORE IN NEONATES: SPINAL VERSUS GENARAL ANAESTHESIA FOR ELECTIVE CAESAREAN SECTION.
}

Sahana K.S ${ }^{1}$

\section{HOW TO CITE THIS ARTICLE:}

Sahana K.S. "Comparison of Apgar score in Neonates: Spinal Versus General Anesthesia for Elective Caesarean Section". Journal of Evolution of Medical and Dental Sciences 2014; Vol. 3, Issue 03, January 20; Page: 538-543, DOI: $10.14260 / J E M D S / 2014 / 1862$

ABSTRACT: Background: 10 point Apgar score has been used to assess the condition and prognosis of newborn infants throughout the world. Objective of the study is to compare the effects of general and spinal anesthesia on Apgar score in newborns of pregnant women undergoing elective caesarean section. STUDY DESIGN: Retrospective observational study. SETTING: This study was conducted in the department of pediatrics between December 2012 to June 2013. SUBJECTS AND METHODS: Recorded Apgar scores of 90 neonates were retrospectively studied after obtaining data from medical records department. Mothers of neonate in Group R (N: 60) underwent caesarean section by spinal anesthesia and mothers of neonates in Group G (N: 30) by general anesthesia. Apgar score $\geq 7$ was considered as Satisfactory to the newborns. ANALYSIS: The data collected was analyzed through statistical package SPSS version 10.0. Descriptive statistics were used to describe the data; independent samples't-test was used to compare quantitative variables. Qualitative variables were compared through chi-square test. $\mathrm{P}$ value $<0.05$ was taken as statistically significant. RESULTS: Apgar score measured at 1 and $5 \mathrm{~min}$, after delivery was $\geq 7$ in 58 (96.66\%) and $60(100 \%)$ neonates in group R, while it was $22(73.33 \%)$ and $28(93.33 \%)$ neonates in group G for regional and general anesthesia respectively. Apgar score $>7$ was observed in significantly more neonates in group $\mathrm{R}$ as compare to group $\mathrm{G}(\mathrm{p}<0.05)$. mean \pm SD values of Apgar score at 01 and 5 minutes was also significantly higher in group $R$ than group $G$ [8.44 \pm 0.51 vs. $6.90 \pm 0.71$ at 01 min and $9.71 \pm 0.25$ vs. $9.04 \pm 0.77$ at $5 \mathrm{~min}](\mathrm{p}<0.001)$. CONCLUSION: Apgar scores were better preserved in neonates born to mother under spinal anesthesia for lower segment elective Cesarean sections.

KEY WORDS: Apgar score, Cesarean section, Spinal anesthesia, General anesthesia, neonate.

INTRODUCTION: The Apgar score was primarily designed as a research tool, enabling the grouping of infants according to their condition at birth. In 1953, Virginia Apgar, M.D. published her proposal for a new method of evaluation of the newborn infant. APGAR score is a clinical test performed on a newborn one and five minutes after birth. It is a composite measure of breathing effort, heart rate, muscle tone, reflexes, and skin color and is an indicator of the newborn's need for medical attention shortly after birth. Apgar score (AS) is routinely used for assessment of newborns immediately after birth and consists of five variables viz. Respiratory efforts, heart rate, color, muscle tone, and reflex irritability. It is being used as a standardized tool for expressing the physiologic condition of newborn at birth and also to record fetal to neonatal transition. However, Apgar score has major limitations like having a limited time frame and including subjective components. Each of these is given a score of 0,1 and 2 . The score is traditionally reported at 1 and 5 min after birth. ${ }^{1} \mathrm{~A}$ score of 0-3 at $5 \mathrm{~min}$ is a suggestive criteria for asphyxial insult and is a predictor of neonatal mortality. Infants with a score of $\geq 7$ are considered normal. ${ }^{1}$ 
Apgar scoring is a research tool rather than a criteria for clinical assessment on which to base management decision or prognosis. Apgar score at 1, 5 min have a low specificity for asphyxia and consequently poor predictive value for long term neurological sequelae. ${ }^{2}$ score can be falsely low in very preterm, maternal drug intake, CHD, and CNS malformations, hence low scores cannot be always equated to asphyxia. However it is useful in assess cardiopulmonary status, tell about need of resuscitation and its effectiveness. It is assigned every $5 \mathrm{~min}$ until $20 \mathrm{~min}$ or till 2 successive score are 7 or greater. The neonatal resuscitation program (NRP) guidelines state that "Apgar scores should not be used to dictate appropriate resuscitative actions, nor should interventions for depressed infants be delayed until the 1-minute assessment." However, an Apgar score that remains 0 beyond 10 minutes of age may be useful in determining whether additional resuscitative efforts are indicated.

The most important cause of fetal distress in any anesthetic method is the reduction in the amount of $\mathrm{O}_{2}$ available to the fetus as a result of the reduction of uteroplacental blood flow. Maternal, placental, and fetal factors play roles in such reduction. The effect of anesthetic drugs is direct or through the changes in the mother. ${ }^{3}$ The Apgar scores are taken at 01 and 05 minutes after delivery. Of the two scores, the 05 minutes score is regarded as the better predictor of survival in infancy in the long term. Whereas the 01 minute score definitely has the value for; assessing the effects of different drugs given to the mother during the Cesarean section. This method is even more appealing because it is non-invasive, 4,5 .

METHODOLOGY: Data was collected from medical records section of our hospital from December 2012 to June 2013, after obtaining ethical committee clearance for the study. Data from 90 patients were collected for study purpose. Exclusion criteria includes Patients with severe pregnancy induced Hypertension on treatment, eclampsia, obstructed labor, fetal distress due to any reason with meconium stained liquor or placenta previa. Data included indication, type of anesthesia, anesthetic drugs given, one and five minute Apgar, neonatal ICU admission, and perinatal death. There were 580 deliveries during the study period of which 145(25\%) was through caesarean section.90 patients were selected, after excluding mothers with fetal distress. data was divided in to two groups of neonates i.e. Group R (N- 60), whose mother was given spinal anesthesia and Group G ( $\mathrm{N}-30)$, whose mother received general anesthesia. All pregnant women with term gestational age 37-40 weeks, ASA-1 or 2, with singleton pregnancy were included. Fetal factors considered were normal growth parameters on ultrasound and clinical examination.

General anesthesia was given by a standardized anesthesia technique by performing rapid sequence induction and intubation with inj. propofol $2 \mathrm{mg} / \mathrm{kg}$, inj. suxamethonium $1.0 \mathrm{mg} / \mathrm{kg}$, and application of Sellick's maneuver. After confirmation of endotracheal tube by auscultation of breath sounds/end tidal $\mathrm{Co}_{2}$, inj. vecuronium $0.1 \mathrm{mg} / \mathrm{kg}$ was given. Maintenance was done on $0.5 \%$ isoflurane in oxygen/nitrous oxide $(50=50)$. After the delivery of baby bolus dose of inj. Fentanyl 1.5 $\mathrm{m} \mu / \mathrm{kg}$ and an infusion of 20 units of oxytocin was given. At the end of surgery when patient resumed some breathing effort, residual effects were reversed with inj. neostigmine $0.35 \mathrm{mg} / \mathrm{kg}$ and inj. glycopyrrolate $0.05 \mathrm{mg} / \mathrm{kg}$. When the patient became fully awake, the endotracheal tube was removed.

Patients in spinal anesthesia group were preloaded with $500 \mathrm{ml}$ of crystalloid solution. Bupivacaine $0.5 \%, 1.8 \mathrm{ml}$ was given at L3-4 or L4-5 interspace in sitting or lateral position. all 
patients were put in supine position after placing a wedge under right buttocks. Supplemental oxygen 4 liter/min was administered via face mask.

Recorded data of Apgar score at 01 and 05 minutes were collected. Newborn outcome was acceptable if the Apgar score was $\geq 7$. The data collected was analyzed through statistical package SPSS version 10.0. Descriptive statistics were used to describe the data; independent samples't-test was used to compare quantitative variables. Qualitative variables were compared through chisquare test. $p$ value $<0.05$ was taken as statistically significant.

\begin{tabular}{|c|c|c|c|c|}
\hline \multicolumn{5}{|c|}{ Apgar Scale (evaluate @ 1 and 5 minutes postpartum) } \\
\hline \multicolumn{2}{|r|}{ Sign } & 2 & 1 & $\mathbf{0}$ \\
\hline A & $\begin{array}{l}\text { Activity } \\
\text { (muscle tone) }\end{array}$ & Active & $\begin{array}{l}\text { Arms and } \\
\text { legs flexed }\end{array}$ & Absent \\
\hline $\mathbf{P}$ & Pulse & $>100 \mathrm{bpm}$ & $<100 \mathrm{bpm}$ & Absent \\
\hline G & $\begin{array}{l}\text { Grimace } \\
\text { (reflex } \\
\text { irritability) }\end{array}$ & $\begin{array}{l}\text { Sneezes, } \\
\text { coughs, pulls } \\
\text { away }\end{array}$ & Grimaces & No response \\
\hline A & $\begin{array}{l}\text { Appearance } \\
\text { (skin color) }\end{array}$ & $\begin{array}{l}\text { Normal over } \\
\text { entire body }\end{array}$ & $\begin{array}{l}\text { Normal } \\
\text { except } \\
\text { extremities }\end{array}$ & $\begin{array}{l}\text { Cyanotic or } \\
\text { pale all over }\end{array}$ \\
\hline $\mathbf{R}$ & Respirations & Good, crying & $\begin{array}{l}\text { Slow, } \\
\text { irregular }\end{array}$ & Absent \\
\hline
\end{tabular}

Fig. 1: APGAR SCORE CHART

RESULTS: Most of the pregnant women were 18 to 30 years of age (93.33\%) in both groups. 90 patients (neonates) were enrolled in the study. all the patients completed the study protocol were included in the data analysis. Thus group $\mathrm{R}$ and group $\mathrm{G}$ consisted of 60 and 30 patients each. There was no significant difference in the demographic data between the study groups [p $>0.05]$ (Table 1).

\begin{tabular}{|l|c|c|c|c|}
\hline Demographic data & Group R(N- 60) & Group G(N -30) & P value & significance \\
\hline AGE & $25.2 \pm 5.80$ & $26.5 \pm 5.24$ & $>0.05$ & NO \\
\hline Primi gravida & 28 & 14 & $>0.05$ & NO \\
\hline Multi gravida & 32 & 16 & $>0.05$ & NO \\
\hline Height & $156.7 \pm 5.21$ & $154.3 \pm 4.87$ & $>0.05$ & NO \\
\hline Weight & $56.54 \pm 8.34$ & $55.47 \pm 7.84$ & $>0.05$ & NO \\
\hline \multicolumn{4}{|c|}{ Table 1: Demographic data (mean \pm SD) in the study groups. } \\
\hline
\end{tabular}

The mean age of the patients received spinal anesthesia was $25.20 \pm 5.80$ years and those received general anesthesia was $26.5 \pm 5.24$ years. Significant difference was not observed in age, parity, height and weight of two groups ( $>>0.05)$. (table 1) 
Mean \pm SD values of Apgar score of neonates at 01 minutes was significantly high in those women who received spinal anesthesia, $8.44 \pm 0.51$ as compared to those who received general anesthesia $6.90 \pm 0.71(\mathrm{p}<0.001)$. Apgar at $5 \mathrm{~min}$ was also significantly high in group $\mathrm{R}$ compare to group G $[9.71 \pm 0.25$ vs. $9.04 \pm 0.77(\mathrm{p}<0.001)]$.

\begin{tabular}{|c|c|c|c|}
\hline Variables & $\begin{array}{c}\text { Group R } \\
\text { (Spinal (Anesthesia) }\end{array}$ & $\begin{array}{c}\text { Group G } \\
\text { (General (Anesthesia) }\end{array}$ & P-Values \\
\hline Apgar at 01 $\mathrm{min}$ & $8.44 \pm 0.51$ & $6.90 \pm 0.71$ & $<0.001$ \\
\hline Apgar at 05 $\mathrm{min}$ & $9.71 \pm 0.25$ & $9.04 \pm 0.77$ & $<0.001$ \\
\hline
\end{tabular}

Table 2: Mean \pm SD comparison OF APGAR between groups.

Acceptable newborn Apgar score i.e. $\geq 7$ at one minute was observed in 22(73.33\%) neonates of Group G while it was observed in 58(96.66\%) neonates in group R. Unsatisfactory Apgar score was observed in $8(26.7 \%)$ neonates in group $\mathrm{G}$ as compared to $2(3.4 \%)$ neonates in group $\mathrm{R}$. acceptable Apgar score at five minutes was observed (Apgar $\geq 7$ ) in all i.e. 60(100\%) neonates in group $\mathrm{R}$ while in group $\mathrm{G}$ it was observed in 28(93.33\%) neonates. acceptable newborn Apgar score was significantly high in group $R$ than group $G(p<0.05)$. [table 3]

\begin{tabular}{|c|c|c|c|c|}
\hline Outcomes & $\begin{array}{c}\text { Group R } \\
\text { (Spinal Anesthesia) } \\
\mathbf{n = 6 0}\end{array}$ & $\begin{array}{c}\text { Group G } \\
\text { (General Anesthesia) } \\
\mathbf{n = 3 0}\end{array}$ & $\begin{array}{c}\text { Total } \\
\mathbf{n = 9 0}\end{array}$ & p-Value \\
\cline { 1 - 3 } Apgar $\geq 7$ & $60(100 \%)$ & $28(92.5 \%)$ & $88(96.3 \%)$ & \multirow{2}{*}{$<0.05$} \\
\hline Apgar $<7$ & $0(0 \%)$ & $2(6.67 \%)$ & $02(3.8 \%)$
\end{tabular}

$2(3 \%)$ infant born by general anesthesia (Group G) required prolong mask ventilation (60 sec) and NICU admission and There was no neonatal mortality

DISCUSSION: Spinal anesthesia has become the preferred anesthesia for cesarean section. Internationally, obstetric anesthesia guidelines recommend spinal and epidural over general anesthesia (GA) for most caesarean sections (CSs).6,7 While there is evidence that GA is associated with an increased need for neonatal resuscitation, ${ }^{8}$ study done by Page et al, suggested that combination of fetal heart rate monitoring, cord blood ph. and Apgar assessment is better than anyone parameter alone for evaluation of fetal status just after delevary. ${ }^{9}$

Our study concluded, Apgar score of neonate at 01, 5 minutes was significantly high in those women who received spinal anesthesia $(9.04 \pm 0.77$ and $9.71 \pm 0.25)$, then when compared to those who received general anesthesia.(6.90 \pm 0.71 and $8.44 \pm 0.51)$. Kolatat et al, 10 and Ong B Y, 11 also found lower Apgar scores in the neonates whose mothers received general anesthesia. ${ }^{10,11}$

Acceptable Apgar score ( $\geq 7$ ) at one minute was observed high in spinal group of 58(96.66\%) neonates when compared to general anesthesia group of 22(73.33\%) neonates. Unsatisfactory Apgar score was observed in $8(26.7 \%)$ neonates in general anesthesia group as compared to 
$2(3.4 \%)$ of the neonates who received spinal anesthesia. Alfredo $\mathrm{M}$ et al, ${ }^{12}$ found lesser depressed newborns $1.1 \%$ in the spinal group compared to $25.9 \%$ in the general group. 12

Acceptable Apgar score ( $\geq 7$ ) at five minutes was significantly high in group $\mathrm{R}$ than group $\mathrm{G}$. In group $\mathrm{R}$, it was observed in all i.e. 60(100\%) neonates while in group $\mathrm{G}$ it was observed in 28(93.3\%) neonates and Apgar score $<7$ were seen in 2(6.7\%) neonates of group G. Tabassum et al, 13, found Apgar scores were higher at 01 and $5 \mathrm{~min}$ in spinal group compare to general anesthesia group $(\mathrm{p}<0.05)$. however some authors found similar Apgar at $5 \mathrm{~min}$ in both the groups. ${ }^{14,15}$ in a study done by Amomani OS, also concluded that regional anesthesia (spinal/epidural) has better Apgar score at 1 and 5 min when compared to general anaesthesia. ${ }^{16}$

According to Robert et al, ${ }^{17}$, no anesthetic method was necessarily safer or hazardous then another and each method has its own liabilities. He showed regional anesthesia was associated with fetal acidemia, and had features of an acute respiratory type of academia and approximately 18\% of infants had umbilical artery blood pH values of 7.19 or less. however some clinical studies suggested that there is little to choose between general and spinal for obstetric anesthesia with regards to their effect on fetal acid and base balance. ${ }^{18}$ However for emergency caesarean section for fetal distress, spinal anesthesia shows better Apgar scores at 1 and $5 \mathrm{~min}$ when compared to general anaesthesia. ${ }^{19,} 20$

CONCLUSION: We observed Apgar score in neonates whose mother received general anesthesia were lower than, neonates whose mothers received spinal anesthesia. Satisfactory Apgar scores were significantly higher in spinal anesthesia group. neonatal outcome is favorable in spinal anesthesia and can be preferred over general anesthesia. It can be further evaluated by a large studies on Apgar scores in neonates following both elective and emergency cesarean sections.

\section{REFERENCES:}

1. American Academy of Pediatrics, Committee on Fetus and Newborn, American College of Obstetricians and Gynecologists and Committee on Obstetric Practice. The Apgar score. Pediatrics. 2006; 117:1444-47.

2. Leuthner SR, Das O G. Low Apgar score and the definition of birth asphyxia. Pediatric clinics of north america.2004 51(3);737-745

3. Petropoulos G, Siristatidis C, Salamalekis E, Creatsas G. Spinal and epidural versus general anesthesia for elective Cesarean section at term: effect on the acid-base status of the mother and newborn. Journal of Maternal-Fetal and Neonatal Medicine. 2003; 13(4):260-66.

4. Skolnick AA. Apgar quartet plays perinatologist's instruments. JAMA 1996; 276:1939-40.

5. Khoury AD, Moretti ML, Barton JR. Fetal blood sampling in patients undergoing elective cesarean section: a correlation with cord blood gas values obtained at delivery. Am J Obstet Gynecol 1994; 171:679-84.

6. American Society of Anesthesiologists Task Force on Obstetric Anesthesia Practice guidelines for obstetric anesthesia: an updated report by the American Society of Anesthesiologists Task Force on Obstetric Anesthesia. Anesthesiology. 2007;106:843-63

7. Cyna AM, Dodd J. Clinical update: obstetric anaesthesia. Lancet. 2007;370:640-42

8. Gordon A, McKechnie EJ, Jeffery H. Pediatric presence at cesarean section: justified or not? Am J Obst Gynecol. 2005;193:599-605. 
9. Page FO, Martin JN, Palmer SM, Martim RW, Lucas JA, Meeks GR et al. Correlation of neonatal acid -base states with Apgar score and fetal heart rate tracing. Am J Obstet Gynecol 1986;154(6)1306-11

10. Ong B Y, Cohen M M, Palahniuk R J. Anesthesia for cesarean section - effects on neonates. Anesth Analg. 1989;68:270-75.

11. Koltat T, Somboonnanonda A, Lertakyamanee J, Chinachot T, Tritrakaran T, Muangkasem J. Effect of general and regional anesthesia on the neonate (a prospective randomized trial). J Med Assoc Thai 1999 Jan; 82(1):40-45.

12. Alfared M, Antonio DV, Anammaria G, Valentina P, Lara M G, Marianna G et al. General versus spinal anesthesia for elective caesarean sections: effects on neonatal short-term outcome. A prospective randomize study. J of Mat-Fet and Neot Med. Posted online Jan 21, 2010.

13. Tabassum R, Sabbal S, Khan F W, Shaikh J M. Comparison of the effect of general and spinal anaesthesia on Apgar score of the neonates in patients undergoing elective cesarean section. Pak J Surg 2010;26(1);46-49

14. Norouzi A, Pazoki S, Darabi M. Comparison of general and spinal anaesthesia effect on neonatal Apgar score in elective cesarean section. A M U J, 2007;10(2):54-61

15. Imtiaz A, Mustafa S, Masroorudin, noor-ul-huq, Ali S H, Imtiaz K. Effect of spinal and general anaesthesia over apgar score in neonates born after elective cesarean section. J L U M H S, 2010;9(3);151-54

16. Almomani O S. Effect of general anesthesia compared to regional anaesthesia on Apgar score of neonates. A J O L;2012, 7(3);179-82

17. Roberts S W, Leveno K J, Sidawi J E, Lucas M J, Kelly M A. Fetal acidemia associated with regional anesthesia for elective cesarean delivery. Obstet Gynecol 1995 Jan;85(1):79-83.

18. Wimmer J E. Neonatal resuscitation, Pediatr Rev 1994;15;225

19. Wahjoeningsih S, Witjaksono W. Evaluation of anaesthesia method in cesarean section for fetal distress. Malaiy J Med Sci 2007, 14(2);41-46

20. Beckmann M, Calderbank S. Mode of anaesthetic for category 1 caesarean section and neonatal outcome. Australian and New Zealand journal of Obstetric and Gynaecology2012;52(4)316-20.

\section{AUTHORS:}

1. Sahana K.S.

\section{PARTICULARS OF CONTRIBUTORS:}

1. Assistant Professor, Department of Paediatrics, Sapthagiri Institute of Medical Sciences and Research Centre, Bangalore.
NAME ADDRESS EMAIL ID OF THE CORRESPONDING AUTHOR:

Dr. Sahana K.S., C/o. Sathish Rao, \#12, Nesara, 2A Cross, Basavasamithi Layout, Vidyaranyapura, Bangalore.

Email -dr_sahana2003@yahoo.co.in

Date of Submission: 21/12/2013.

Date of Peer Review: 23/12/2013.

Date of Acceptance: 09/01/2014.

Date of Publishing: 14/01/2014. 